\title{
CAPITAL SOCIAL E CONFIANÇA: QUESTÕES DE TEORIA E MÉTODO ${ }^{1}$
}

\author{
Bruno Pinheiro W. Reis
}

\begin{abstract}
RESUMO
Este artigo empreende uma discussão de natureza teórico-metodológica da problemática levantada por Robert D. Putnam em Making Democracy Work, de 1993. Perseguindo tanto sua estrutura lógica quanto afinidades analíticas com literatura anterior, o trabalho procura enfocar principalmente os significados teóricos e empíricos dos conceitos de "capital social" e "confiança". Conclui pela identificação de uma agenda de pesquisa certamente promissora, mas patentemente "imatura”, do ponto de vista tanto da operacionalização empírica da teoria quanto mesmo da especificação analítica precisa do significado de suas categorias centrais.
\end{abstract}

PALAVRAS-CHAVE: capital social; confiança; Robert D. Putnam; teoria democrática; escolha racional; pluralismo.

\section{INTRODUÇÃO}

Desde a publicação de Making Democracy Work, por Robert Putnam e seus colaboradores, em 1993, já se produziu extensa literatura em torno de suas principais teses; especulações em torno das relações entre conceitos até então pouco usuais na Ciência Política - como capital social, confiança interpessoal etc. - tornaram-se comuns nas salas de aula das pós-graduações mundo afora, alcançando até mesmo os relatórios e recomendações das principais instituições multilaterais de fomento, como o Banco Mundial2 ${ }^{2}$.

Todavia, em que pesem os claros méritos do trabalho de Putnam quanto ao esforço de síntese de 20 anos dedicados a pesquisa empírica cuidadosa da vida política na península italiana, a elaboração teórica em que o trabalho pretende fundamentar suas principais conclusões ficou condenada às duas dezenas de páginas do capítulo final do livro, e - embora envolva algumas intui-

1 Quero agradecer a Célia Colen, Fernando Filgueiras, Magna Inácio, Maria Aparecida Machado Pereira e Paulo Magalhães Araújo - interlocutores constantes durante o período em que o presente trabalho foi concebido - e a Fábio Wanderley Reis, que fez numerosas sugestões tópicas a uma primeira versão do trabalho, induzindo-me a um tratamento mais claro de pontos inicialmente obscuros.

2 Isso pode ser facilmente constatado com uma visita à página especificamente dedicada ao tema do capital social no portal do Banco Mundial (2003). ções promissoras - deixa muitas perguntas sem resposta, legando para a sua posteridade o trabalho de detalhar de maneira mais sólida a estrutura analítica do argumento.

O presente trabalho pretende constituir-se em um modesto exercício de identificação de algumas questões particularmente salientes a que se tem referido certa literatura, com o intuito de contribuir para a explicitação de alguns temas que merecem pesquisa e especificação analítica mais precisa. Para tanto, após uma breve exposição do que entendo como a estrutura lógica básica da teoria esboçada por Putnam no capítulo 6 de seu Making Democracy Work, procurarei identificar algumas questões analíticas ainda em aberto na literatura quanto ao significado operacional dos conceitos de "capital social" e de "confiança interpessoal", com o foco permanentemente voltado para as relações porventura identificáveis entre ambos. A motivação imediata do trabalho prende-se antes de mais nada a um exercício de autoesclarecimento, mas espera-se que as questões aqui abordadas interessem também aos inúmeros colegas que hoje procuram se debruçar sobre o tema.

\section{FAZENDO A DEMOCRACIA FUNCIONAR? OS CÍRCULOS VICIOSOS E VIRTUOSOS DE PUTNAM}

Um dos paradoxos mais salientes do argumento apresentado por Putnam em seu livro de 1993 é o 
fato de que a conotação voluntarista do título original (Making Democracy Work) encontra no conteúdo do livro talvez a mais enfática desautorização a que já se atreveu a Ciência Política, quanto às perspectivas de sucesso de intervenções voluntárias da ação humana voltadas para melhorar o desempenho de qualquer conjunto de instituições políticas em um território dado.

Partindo da familiaridade advinda de suas décadas de experiência de pesquisa sobre a política italiana, Putnam dedicou seu livro a tentar responder por que, afinal, as instituições políticas das diversas províncias italianas podem exibir desempenhos tão díspares de umas províncias para outras, já que todos os governos regionais dispõem, afinal, de instituições políticas rigorosamente idênticas. De fato, poucas vezes cientistas sociais terão tido à sua disposição um caso tão parecido com um experimento desenhado em laboratório: em 1970 o Parlamento italiano atribuiu autonomia política às províncias, $\mathrm{e}-\mathrm{no}$ mesmo gesto - outorgou a todas as mesmas instituições políticas, que passariam, dali em diante, a reger todos os governos regionais que então se constituíam (PUTNAM, 1997, p. 34-41). Com esse gesto, o Parlamento inadvertidamente propiciou aos cientistas sociais interessados no desempenho das instituições políticas um experimento em que se mantinham constantes as instituições enquanto faziam-se variar (dada a grande heterogeneidade regional da sociedade italiana) as condições sociais e econômicas em que deveriam operar essas instituições.

O resultado - previsível - foi que, de fato, não obstante as instituições idênticas, os governos de certas regiões funcionaram muito melhor do que os de outras. Apoiado na elaboração de um indicador efetivamente complexo e abrangente de desempenho institucional, Putnam e seus colaboradores saíram em busca da identificação de alguma variável sócio-cultural ou econômica cuja variação correspondesse às oscilações inter-regionais do seu índice de desempenho institucional. Encontraram uma correlação positiva bastante boa com um índice de modernidade econômica $(r=0,77)^{3}$, mas também uma correlação positiva verda-

3 Putnam (1997, p. 222) assim explica a sua medida: “A modernidade econômica é aqui medida por um escore deiramente espantosa com um índice relativamente idiossincrático de "comunidade cívica" $(\mathrm{r}=0,92)^{4}$.

Durante uma primeira leitura, a sugestão de que essa correlação se mostre espúria, com ambas as variáveis oscilando conjuntamente em obediência a alguma terceira, é muito forte. Particularmente, tende a passar pela cabeça do leitor a possibilidade de que ambas devam-se aos níveis particularmente altos de bem-estar econômico observáveis no Norte da Itália, que favoreceriam tanto uma conduta pessoal caracterizável como "cívica" quanto o bom desempenho das instituições políticas, presumivelmente abastecidas pelos recursos públicos mais abundantes do que no Sul. Putnam, porém, reforça seu ponto ao indicar que a correlação entre comunidade cívica no passado e desenvolvimento econômico no presente é mais forte do que sua recíproca (idem, p. 162-172). Cuidadoso, ele trata de testar e refutar no próprio texto a contestação óbvia segundo a qual a comunidade cívica poderia ser ela própria um subproduto, resultado de níveis presumivelmente mais elevados de dinamismo econômico no Norte da Itália. Se o Norte é hoje mais rico, nem sempre foi-e, ademais, a correlação do desempenho institucional com alguns indicadores do grau de "comunidade cívica" é consistentemente mais elevada que com os indicadores de desenvolvimento econômico. Sabemos que altas correlações por si só não nos provêem uma boa teoria e a arbitrariedade dos indicadores (principalmente os de "comunidade cívica") aconselha-nos cautela quanto à análise e interpretação desses dados. Mas a evidência acumulada por Putnam desafiava com boas razões pelo menos as contestações mais elementares.

Seja como for, aqui nos interessa menos a validação empírica das teses de Putnam do que a

fatorial baseado na renda per capita e no produto regional bruto, nas parcelas da força de trabalho empregadas na agricultura e na indústria, e nas parcelas do valor adicionado correspondentes à agricultura e à indústria, tudo isso no período 1970-77. Há uma estreita correlação entre esses componentes (ponderação média $=0,90$ )".

4 O índice de comunidade cívica adotado por Putnam (1997, p. 110) compõe-se de quatro variáveis: comparecimento a referendos (1974-1987) e leitura de jornais (1975) com carga fatorial positiva, e voto preferencial (19531979) e escassez de associações desportivas e culturais (1981) com carga fatorial negativa. 
inquirição detalhada de seu conteúdo analítico ${ }^{5}$. Com efeito, para as finalidades do presente trabalho o aspecto mais importante do livro de Putnam reside no esboço dedutivo que leva a cabo, no último capítulo, sobre as razões pelas quais se dá a relação empiricamente constatada - a lógica situacional subjacente. E isso é feito - de maneira talvez surpreendente para os mais habituados a contraposições frontais entre explicações "culturalistas" e outras "individualistas" - pelo recurso, ainda que um tanto impressionístico, a raciocínios próprios da abordagem da "escolha racional", incorporando sobretudo a lógica da ação coletiva tal como descrita por Olson (1965) - de fato, um "dilema do prisioneiro", no jargão da teoria dos jogos. Muito resumidamente, Putnam aponta duas dinâmicas arquetípicas para o problema do desempenho institucional (que ele - talvez abusivamente - passa nesse ponto a fazer corresponder ao problema hobbesiano da instauração da ordem): uma que ele chama o "círculo vicioso autoritário" e a outra, em contraste, o "círculo virtuoso democrático".

Na primeira, o Estado (ou seus aliados, potentados locais privados) garante a ordem de maneira precipuamente coercitiva, por meio do medo e da repressão, deixando em segundo plano a construção de qualquer relação de confiança mútua disseminada entre os habitantes. Na segunda, investe-se no estabelecimento de regras impessoais que devem, em princípio, ser seguidas por todos, economicamente poderosos ou não. Esta última depende, para sua consecução eficaz, da generalização da disposição de firmar compromissos e abrir mão de ganhos imediatos em favor de compensações futuras, na presunção de que a observância universal de determinadas regras renderá frutos no longo prazo. $\mathrm{O}$ arranjo autoritário é um "círculo vicioso" porque o precedente da afirmação violenta do poder inibe a disseminação de comportamentos mais cooperativos no interior da população. A vontade do poderoso de plantão prevalece em última instância, dificultando o estabelecimento de laços "horizontais" de confiança mútua e tornando inúteis, por pouco

5 Há extensa literatura de trabalhos breves de caráter polêmico sobre o livro de Putnam. Para ficarmos apenas com alguns que me são imediatamente acessíveis, podemse mencionar Burkhart e Lewis-Beck (1994), Goldberg (1996), Levi (1996), Tarrow (1996), Prates (1997) e Jackman e Miller (1998). confiáveis, compromissos que envolvam compensações futuras. A democracia, por sua vez, constituiria um "círculo virtuoso" em virtude do fato de que o acatamento de regras impessoais de solução de disputas, uma vez estabelecido, pode gerar um estado de coisas no qual a violação dessas regras, mesmo que imediatamente proveitosa, pode tornar-se onerosa para aquele que a pratica, em virtude da retaliação dos demais (PUTNAM, 1997, p. $163-185)^{6}$.

Não será irrelevante sublinhar que o argumento é perfeitamente análogo à solução do dilema do prisioneiro pela reiteração infinita do jogo com base em um comportamento tit-for-tat, tal como originariamente demonstrada por Michael Taylor (1976) e experimentalmente corroborada por Robert Axelrod (1984). Nesse caso, os atores seriam induzidos à cooperação por medo da retaliação de seu adversário: se cada "jogador" tem motivos para esperar que seu oponente comportese da mesma maneira que ele próprio, então pode ser racional cooperar, se cada um valorizar suficientemente seus resultados futuros. Se, todavia, parte-se da situação descrita pela teoria dos jogos como "egoísmo universal", ou seja, uma situação em que todos adotam a estratégia inicial de não cooperar, então a cooperação não emergirá espontaneamente, exceto sob a condição - bastante restritiva - de que uma população em equilíbrio não-cooperativo veja-se "invadida" por um cluster internamente cooperativo, que mantenha pouco contato com a população majoritária (nãocooperativa), e que nesses poucos contatos disponha-se a adotar uma política de retaliação (" $t i t$ for-tat") em relação aos não-cooperativos (ZAGARE, 1984, p. 58-62). Além disso, se os atores encontram-se imersos em um ambiente em que as regras não costumam ser estáveis, tornando plausível a possibilidade de que o "jogo" seja interrompido a qualquer momento, então - mesmo que se parta da cooperação universal - todos serão induzidos a abandonar a estratégia cooperativa antes que seu oponente faça-o, já que existe a possibilidade de a retaliação ser impossibilitada pela interrupção abrupta do "jogo", suspensão das regras

\footnotetext{
6 De maneira análoga, Wanderley Guilherme dos Santos (1993, p. 105-106) refere-se a um "jogo de espelhos" para descrever o comportamento do "conjunto de expectativas que os indivíduos têm quanto ao governo, quanto aos seus concidadãos e quanto a si próprios" - expectativas que comporiam, grosso modo, a "cultura cívica" local.
} 
vigentes e imposição arbitrária de novas regras.

É por isso que Putnam (1997, p. 186-187) afirma que a "solução hobbesiana" - isto é, o círculo vicioso autoritário - é não só um equilíbrio estável (ou não seria um “círculo vicioso"), mas também mais estável que a solução cooperativa do "círculo virtuoso democrático". Isso porque a generalização da estratégia da não-cooperação incondicional sempre permanece como uma possibilidade de comportamento estável a longo prazo, uma vez alcançada - ao contrário da solução cooperativa, que dependerá sempre de uma taxa de desconto suficientemente baixa na preferência temporal dos atores, de modo a permitir que eles abram mão da possibilidade de um ganho imediato que seria propiciado pelo abandono da estratégia cooperativa, em nome de evitar-se um equilíbrio pior no futuro (ou seja, a cooperação universal é, na melhor das hipóteses, um equilíbrio condi(ional). Mais importante ainda: o contexto em que estão imersos os atores deverá permitir-lhes abrir mão de ganhos imediatos com alguma segurança de que não serão impedidos de desfrutar de seus ganhos esperados no futuro 7 .

Assim, a interpretação que Putnam empresta a seus dados corrobora fortemente a análise do dilema do prisioneiro realizada por Taylor. De um lado, a existência de laços de confiança mútua reforça os mecanismos de cooperação entre os habitantes e favorece o desempenho das instituições políticas; esse mesmo desempenho institucional eficiente atua positivamente sobre o contexto, reduzindo a incerteza e reforçando ainda mais o nível de confiança e cooperação no interior da população - esse o círculo virtuoso democrático. De outro lado, na ausência de formas espontâneas de cooperação, a ordem impõe-se por uma organização hierárquica vertical da autoridade e - onerosamente - pela força. As instituições, subordinadas à vontade dos poderosos do momento, funcionam precariamente (quando não mudam constantemente), submergindo os atores em um elevado grau de incerteza quanto ao futuro e inviabilizando qualquer disposição de abrir-se mão

7 Barbara Geddes (1994, p. 29-30) também aponta os efeitos deletérios da incerteza sobre as possibilidades de cooperação, sublinhando o fato de que contextos instáveis como os que costumam viger no Terceiro Mundo tendem a elevar significativamente o desconto de pay-offs futuros. de ganhos imediatos com apoio em uma presunção de reciprocidade futura. O mau desempenho institucional reafirma e reforça, assim, os traços de desconfiança mútua disseminados no interior da população, completando a lógica do chamado "círculo vicioso autoritário"8.

Vale a pena destacar aqui o curioso lugar ocupado pela categoria "confiança" no argumento de Putnam. Em um livro abundante em evidência empírica, ela é elevada no último capítulo à condição de crucial mecanismo causal do argumento - mas ela mesma não é objeto de qualquer tentativa de mensuração empírica. Não há um índice de confiança interpessoal em Putnam. Embora seu argumento acabe alçando vôos mais altos, é preciso lembrar que o propósito inicial de Putnam é modesto. Ele não está investigando, em princípio, algo genericamente descritível como "as condições sociais (ou culturais) da democracia" - mas sim buscando a explicação para diferenciais de desempenho de instituições (democráticas) idênticas em

\footnotetext{
8 A aproximação aqui efetuada entre Putnam e Taylor é compatível com a importância atribuída por Margaret Levi (1990, p. 407-410) à vigência do que ela chama de "consentimento contingente" (contingent consent) na estabilidade de uma instituição qualquer. Ali, Levi ajunta à coerção, aos "pagamentos paralelos" (side payments) e às normas um quarto mecanismo de indução à obediência: a obtenção de um consentimento apoiado em uma norma de fairness ("justiça"). Segundo a exposição de Levi (idem, p. 409-410), "[...] part of contingent consent is conditional cooperation $[. .$.$] in which low discount rates, repeated$ interactions, knowledge of others and reciprocity over time permit the emergence of rational decisions to comply. In the case of formal institutions, an individual's cooperation or compliance is conditional upon the provision of promised benefits by institutional managers and personnel and upon the continued compliance of others. No one wants to be a sucker. Thus, any particular individual's decision to comply is based on confidence that others are doing their share" [“[...] parte do consentimento contingente é cooperação condicional [...] em que baixas taxas de desconto, interações repetidas, conhecimento dos outros e reciprocidade ao longo do tempo permitem a emergência de decisões aquiescentes racionais. No caso das instituições formais, a cooperação ou aquiescência de um indivíduo é condicionada pela provisão de benefícios prometidos por administradores e funcionários institucionais e pela aquiescência contínua dos outros. Ninguém quer ser um otário. Assim, qualquer decisão de um indivíduo particular em aquiescer baseia-se na confiança de que os outros estejam fazendo sua parte" Nota do revisor]. Não é por mera coincidência que Levi remete esta fundamentação a Michael Taylor (1987), de fato fundamentalmente uma versão revista de Taylor (1976).
} 
contextos sociais distintos. Identifica uma variável independente tremendamente relevante em seu "índice de comunidade cívica", que inclui medidas de comparecimento a referendos, leitura de jornais, proliferação de associações desportivas e culturais e uma proxy de identificação partidária. Especulando sobre os mecanismos que poderiam prover uma explicação da extraordinária correlação encontrada, recorre à noção de "capital social" (que passa a substituir a idéia de "comunidade cívica") e produz a conjectura de que seria a confiança interpessoal o mecanismo por excelência pelo qual o capital social produziria seus efeitos sobre o desempenho institucional.

Mas isso é tudo, quanto à confiança. Essa última conjectura jamais é, ela mesma, testada empiricamente; sequer são sugeridas estratégias de operacionalização empírica posterior do conceito de confiança. Essa lacuna, de resto perfeitamente compreensível em um livro que afinal já cumpria ali a tarefa de oferecer uma resposta fundamentada para o problema que formulara, lega para a literatura posterior as tarefas da especificação conceitual e da operacionalização empírica dessa categoria-chave da teoria proposta por Putnam: a confiança.

\section{PERSEGUINDO ELOS: O ARGUMENTODE PUTNAME SEUS ANTEPASSADOS}

Adiante voltaremos a essas categorias mais detalhadamente. Antes, cabe descermos um pouco mais atentamente sobre o conteúdo substantivo da teorização de Putnam em seus próprios termos, para apontar que o argumento apresentado - apesar da forma original que lhe é conferida e do farto repertório de técnicas mobilizado - não chega a constituir-se propriamente em uma inovação teórica, mas antes na reafirmação de um argumento de longa tradição na Ciência Política moderna, mediante a provisão de uma alentada corroboração empírica. Lembremo-nos, por exemplo, de que Samuel Huntington (1975, p. 16-17) nos anos 1960 apresentava seu argumento sobre a importância da institucionalização (comumente tido como conservador e mesmo pouco democrático) a partir da constatação de um problema derivado da expansão da igualdade da participação política quando esta se dá sem a concomitante expansão da "arte da associação", contrariando a máxima de Tocqueville segundo a qual esta deve crescer na mesma proporção em que se expande a "igualdade de condições".
O livro de Huntington partia da constatação empírica de que nos países periféricos, de modernização tardia, a igualdade política (expressa no direito à participação) desenvolveu-se muito mais rapidamente que as instituições políticas - o que explica seu foco sobre o problema da "institucionalização", sobretudo estatal ${ }^{9}$. Mas, ainda assim, a diferença fundamental entre Putnam e Huntington é muito mais formal que substantiva, pois enquanto Putnam pergunta-se $o$ que faz as instituições funcionarem e encontra resposta na "arte da associação" (para usar a expressão de Tocqueville), estabelecendo nexo causal entre "comunidade cívica" e desempenho institucional, Huntington pergunta-se como fazer instituições que funcionem, e nas primeiras páginas de seu livro praticamente identifica, implicitamente, a ausência da "arte da associação" com a fragilidade das instituições. Ainda que o desdobramento da sua exposição venha a qualificar esta identificação, sob o enquadramento inicial de Huntington, associarse é institucionalizar. O raciocínio implícito é que, ao estabelecerem-se múltiplas associações "horizontais" no interior da população, multiplicam-se os laços de interdependência recíproca entre os habitantes, fundamentais na produção da coordenação de expectativas necessária para assegurarse alguma previsibilidade no comportamento alheio - em uma palavra, criam-se as organizações, que Huntington (idem, p. 19) - em seu realismo eventualmente autoritário-julgou mais importantes que a realização de eleições ${ }^{10}$.

Convém lembrar que também em William Kornhauser (1959), que igualmente se ocupou da problemática legada por Tocqueville, era a baixa disponibilidade das não-elites que distinguia a sociedade pluralista da sociedade de massa - ou

\footnotetext{
9 Robert Dahl (1997, p. 51-62) endossa o ponto no capítulo sobre "seqüências históricas" de seu clássico Poliarquia. Também ali, a propósito, alude-se à confiança: em duas breves páginas de um longo capítulo (49 páginas) dedicado às "crenças dos ativistas políticos" (idem, p. 147-149). Não deixa de manifestar-se naquela passagem uma superposição entre confiança interpessoal e confiança nas instituições: Dahl alude à Itália apenas para remeter a comentário de Joseph LaPalombara sobre a falta de confiança dos italianos nas instituições e nos atores políticos. Sinal dos tempos.
}

10 Admita-se desde logo que, neste como em outros pontos, a estrutura analítica do argumento de Huntington permanece um tanto ambígua, e ocasionalmente obscura. Seja como 
seja, a sociedade que se pode presumir verdadeiramente democrática daquela que, embora mobilizada, queda-se à mercê da condução do seu líder. Partindo da descrição da "sociedade de massas" como caracterizada por alta acessibilidade das posições de elite e, igualmente, alta disponibilidade das não-elites para eventual manipulação como recurso de poder (Tabela 1), Kornhauser (1959, p. 31) distingue duas críticas opostas à sociedade de massas: uma aristocrática, como a de Ortega y Gasset em A rebelião das massas (temerosa quanto à "hiperdemocracia") e outra democrática, como a de Hannah Arendt em As origens do totalitarismo (temerosa em relação à "tirania ilimitada"). A primeira crítica - aristocrática - concentrar-se-ia na alta acessibilidade das posições de elite para explicar a natureza conflituosa e instável da sociedade de massas, deixando de fazer distinção entre esta e a "sociedade pluralista", que se caracterizaria por alta acessibilidade das elites, mas com baixa disponibilidade das não-elites. A crítica democrática, por sua vez, preocupa-se sobretudo com os efeitos nefastos que a eventual fragilidade dos laços associativos intermediários - típica da sociedade de massas - venha a produzir no que tange à disponibilidade das não-elites. Aqui, para Kornhauser, deixa-se de distinguir a sociedade de massas da "sociedade totalitária", caracterizada por alta disponibilidade das não-elites, mas baixa acessibilidade das elites.

TABELA 1 - TIPOS DE SOCIEDADE CONFORME A ACESSIBILIDADE DAS ELITES E A DISPONIBILIDADE DAS NÃO-ELITES

\begin{tabular}{|c|c|c|c|}
\hline \multicolumn{2}{|c|}{} & \multicolumn{2}{|c|}{ Disponibilidade das não-elites } \\
\cline { 3 - 4 } \multicolumn{2}{|c|}{} & Baixa & Alta \\
\hline $\begin{array}{c}\text { Acessibilidade } \\
\text { das elites }\end{array}$ & Baixa & sociedade comunal & sociedade totalitária \\
\cline { 2 - 4 } & Alta & sociedade pluralista & sociedade de massas \\
\hline
\end{tabular}

FONTE: Kornhauser (1959, p. 40).

Mesmo que se admita a presença de alguma dose de inevitável esquematismo nesse quadro, ele tem o mérito de explicitar uma lógica subjacente à importância do associativismo autônomo no adequado funcionamento da democracia moderna, por ajudar a manter baixa a disponibilidade das não-elites no que toca a mobilizações orientadas "de cima" - ou, como se costuma dizer, "orquestradas" por elites. Diferentemente da visão usual da crítica "aristocrática", para Kornhauser (idem, p. 34-35) a alta acessibilidade das posições de elite não é condição suficiente (embora seja necessária) para a emergência dos males da "política de massas" - seria igualmente necessária a alta disponibilidade das não-elites. Similarmente,

for, observe-se que não chego a atribuir-lhe a tese de que "toda associação é uma instituição". Minha interpretação atribui-lhe uma versão mais fraca dessa relação: o que se afirma é que "associar-se é institucionalizar", ou seja, deflagrar um processo de institucionalização, que, todavia, pode vir ou não a consumar-se. Isto é, uma associação, uma vez criada, pode vir ou não a transformar-se em uma organização adaptável, complexa, autônoma e coesa - para usar os atributos imaginados pelo próprio Huntington (1975, p. 23-36). ao contrário do que se depreende da "crítica democrática", uma alta disponibilidade das nãoelites não seria suficiente para caracterizar uma sociedade totalitária, que requereria igualmente uma baixa acessibilidade das posições de elite. Assim, em Kornhauser obtivemos, mediante a fórmula "alta acessibilidade das elites e baixa disponibilidade das não-elites", um guia básico para uma política pluralista que tente evitar os males da massificação na sociedade moderna. É quase desnecessário sublinhar, a esta altura, que Putnam (1997) produz uma enfática corroboração empírica das conclusões de Kornhauser no que concerne a esse tópico.

Mas tanto Huntington como Kornhauser seguem de perto, nesse ponto, a melhor tradição pluralista da Ciência Política norte-americana - do elogio às "filiações múltiplas". Expressamente advogada nos Federalist Papers, particularmente no Artigo n. 10, sobre o problema das facções, a tese da proliferação das facções foi inicialmente brandida contra certa recepção de Rousseau e Montesquieu, para quem a sobrevivência das repúblicas dependeria da virtude dos cidadãos e da eliminação de todo facciosismo interno. 
Madison constatou rapidamente que essa eliminação seria incompatível com um governo livre - e, embora toda a tradição apelasse à virtude como fundamento do governo popular, o mundo que o cercava parecia muito pouco propício a tal expectativa. Como se sabe, ele veio a prescrever a solução contrária, que ditaria o tom da Ciência Política do século XX: a proliferação das facções, de maneira a impedir-se que qualquer delas alcançasse posição majoritária, logrando, assim, sua neutralização recíproca ${ }^{11}$.

Em um contexto como esse, será incumbência do governo atuar, por meio do monopólio do uso legítimo da força, como mediador em última instância dos acordos, costumes e valores oriundos da livre interação e cooperação - e, naturalmente, também dos conflitos - entre os indivíduos e grupos diversos na sociedade. Ele permanece, de qualquer maneira, sendo ator crucial para o funcionamento das instituições, isoladamente de longe o mais importante, poderosamente capaz de influenciá-las - para melhor ou pior - tanto no seu formato quanto no seu desempenho. Pois é somente ao constituir a forma legal que lhe permitirá desempenhar seu papel de fiador dos acordos firmados no interior da sociedade que o governo propriamente institucionaliza esses acordos; transforma acordos circunstanciais ou formas momentâneas de cooperação em instituições propriamente ditas.

A alusão ao papel desempenhado pelo Estado nessa problemática permite trazer à baila um último antecessor da contribuição de Putnam que nos parece merecer menção. Trata-se de Gabriel Almond (1966) e sua abordagem abertamente funcionalista do estudo comparativo da política, particularmente bem-vinda se se têm em mente as dificuldades que enfrentavam em seu tempo as tentativas de generalizarem-se seqüências históricas típicas para o processo de construção do estado nacional ${ }^{12}$. Pois, adotando um marco parsoniano de referência teórica geral, Almond relega a segundo plano considerações históricas

\footnotetext{
11 Para uma breve exposição do teor do "Federalista" n. 10, pode-se recorrer a Fernando Limongi (1989, p. $252-$ 255).

12 É numerosa a bibliografia relevante produzida por Almond, sendo particularmente célebre Almond e Powell (1966). Aqui me apóio, todavia, em Almond (1966), em que se apresentam resumidamente alguns dos temas centrais daquele livro.
}

(diacrônicas) para deter-se nas condições hipotéticas de operação do subsistema político no interior da sociedade como um todo. Aqui, mais que sua descrição do "interior" do sistema político por suas "funções de conversão" de inputs em outputs $^{13}$, interessam-nos suas considerações sobre o desempenho do sistema político em seu ambiente a partir da distinção entre cinco "capacidades" (capabilities) a serem desenvolvidas pelo sistema: extrativa, reguladora, distributiva, simbólica e responsiva. Excetuada a capacidade responsiva, que se define pela relação entre outputs do sistema e os inputs recebidos de seu ambiente, as outras quatro "capacidades" relativas ao desempenho do sistema político dizem respeito especificamente a outputs (ALMOND, 1966, p. 109). Como seria de esperar-se, essas "capacidades" correspondem em larga medida às "crises" do desenvolvimento político identificadas na colaboração com Lucien Pye nas pesquisas então patrocinadas pelo Social Science Research Council $(\mathrm{SSRC})^{14}$. Mas a elaboração particular de Almond permite-nos manejar mais facilmente determinadas relações lógicas entre os componentes analíticos do sistema, livres de considerações muito detalhadas - necessariamente em alguma medida arbitrárias - sobre "crises" ou "sequiências" históricas efetivamente ocorridas aqui ou ali (ainda que Almond pretenda, sim, estabelecer uma sequiência de desenvolvimento típica). Dessa forma, a seqüência das crises que se encontra idealmente - ainda que de maneira um tanto forçada -

13 Almond (1966, p. 104) sugere uma classificação das funções de conversão em seis tipos: "(1) the articulation of interests or demands, (2) the aggregation or combination of interests into policy proposals, (3) the conversion of policy proposals into authoritative rules, (4) the application of general rules to particular cases, (5) the adjudication of rules in individual cases, and (6) the transmission of information about these events within the political system from structure to structure and between the political system and its social and international environments" ["(1) a articulação de interesses ou demandas; (2) a agregação ou combinação de interesses em propostas de políticas; (3) a conversão de propostas de políticas em regras dotadas de autoridade; (4) a aplicação de regras gerais a casos particulares; (5) a adjudicação das regras em casos individuais e (6) a transmissão da informação sobre esses eventos no sistema político de estrutura para estrutura e entre o sistema político e seus ambientes social e internacional" - N. R.].

14 São vários os livros sobre "desenvolvimento político" publicados sob os auspícios do Social Science Research Council durante os anos 1960. Um volume-síntese do programa de pesquisa pode ser encontrado em Binder (1971). 
esboçada nos trabalhos da série do SSRC sobre desenvolvimento político pode encontrar nos trabalhos de Almond uma correspondência mais fundamentada em considerações sobre a maneira como a capacidade do sistema político de desempenhar determinadas funções condiciona ou não sua capacidade de cumprir outras funções. Assim, por exemplo, Almond pôde substituir a seqüência das "crises" pela postulação da anterioridade lógica da capacidade extrativa frente às demais (ou, melhor dizendo, pela postulação da dependência de todas as demais capacidades em relação à extrativa), bem como condicionar a capacidade distributiva à capacidade reguladora: "What we have said about political capabilities suggests a logic of capability analysis. An extractive capability implies some regulation and distribution, though these consequences may be unintended. A regulative capability implies an extractive capability, if only to gain the resources essential to regulation; and it is difficult to conceive a regulative capability which would not in some way affect the distribution of values and opportunities. They are not only logically related. They suggest an order of development. Thus political systems which are primarily extractive in character would appear to be the simplest ones of all. They do not require the degree of role differentiation and specialized orientations that extractive-regulative systems or extractive-regulative-distributive ones do. Regulative systems cannot develop without extractive capabilities; thus the development of the one implies the development of the other. Increasing the extractive capability implies an increase in the regulative capability, as when, for example, political systems move from intermittent collection of tribute or raids to some form of regularized taxation. Similarly, a distributive system implies an extractive capability, and obviously can reach a higher distributive level if it is associated with a regulative capability as well" 15 (idem, p. 108).

Mas além das "capacidades" relacionadas ao desempenho do sistema, é igualmente relevante

15 "O que dissemos sobre capacidades políticas sugere uma lógica da análise de capacidades. Uma capacidade extrativa implica alguma regulação e distribuição, embora essas conseqüências possam ser não-intencionais. Uma capacidade regulatória implica uma capacidade extrativa, quando nada para ganhar os recursos essenciais à regulação; e é difícil conceber uma capacidade regulatória que não sua capacidade de gerar apoio, que Almond chama "the support aspect of capability"16. Almond não o afirma nesses termos, mas a capacidade de gerar apoio caracteriza-se, inversamente às demais capacidades, como um output da população em resposta a inputs fornecidos pelo sistema político. Pela relação entre o que o sistema político efetivamente obtém comparativamente àquilo que ele demanda da população. Nas palavras de Almond (idem, p. 111), “[...] the support aspect of capability has to be measured [...] in terms of the resources delivered in relation to the resources levied, the obedience accorded in proportion to the obedience required, the allocations accepted in relation to the allocations imposed, the responsiveness of the population to symbolic outputs in relation to that which is expected" 17.

Constituindo, segundo Almond (idem, p. 111112), uma "reserva" de autoridade do sistema, essa capacidade de gerar apoio pode em princípio ser tomada como base empírica aproximada da noção de "cultura política", caracterizada a partir das diferentes propensões de diversos estratos da população a apoiar seu sistema político ("support propensities").

Para Almond, a análise das "capacidades" do sistema político poderia ajudar a preencher o hiato existente entre os estudos "científicos" e os

afete, de alguma forma, a distribuição de valores e oportunidades. Elas estão relacionadas não apenas logicamente. Elas sugerem uma ordem de desenvolvimento. Assim, sistemas políticos de característica primariamente extrativa pareceriam ser os mais simples de todos. Eles não requerem o grau de diferenciação de papéis e de orientações especializadas que os sistemas extrativo-regulatórios ou os extrativo-regulatório-distributivos requerem. Sistemas regulatórios não podem desenvolver-se sem capacidades extrativas; assim, o desenvolvimento de um implica o desenvolvimento do outro. Aumentar a capacidade extrativa implica um aumento da capacidade regulatória, como quando, por exemplo, sistemas políticos passam da cobrança intermitente de tributos ou da rapinagem para alguma forma de taxação regularizada. Similarmente, um sistema distributivo implica uma capacidade extrativa, e obviamente pode alcançar um nível distributivo mais alto se está associado também a uma capacidade regulatória" [N. R.].

16 Algo como "aspecto de apoio da capacidade" [N. R.].

17 " [...] $\mathrm{O}$ aspecto de apoio da capacidade tem que ser medido [...] em termos dos recursos entregues em relação aos recursos tributados, a obediência acordada em proporção à obediência requerida, as alocações aceitas em relação às alocações impostas, a responsividade da população aos produtos simbólicos em relação àquela que é esperada" [N. R.]. 
normativos do sistema político, ao acrescentar o "what" ao "who" e ao "how" típicos da Ciência Política do século XX - ou seja, ao acrescentar "substância" às discussões de procedimento que ocuparam o núcleo da Ciência Política contemporânea. Ao fazer isso, o sistema de Almond incorpora uma inequívoca dimensão normativa à análise, sem renunciar à investigação empírica das condições práticas de funcionamento do sistema político. E aqui Almond parece tocar rapidamente em um ponto que pode ter implicações importantes para o presente trabalho. A especificação de um elenco de tarefas a serem desempenhadas pelo sistema político a partir de uma definição, mais abrangente (de natureza parsoniana), da própria "função política" coloca-nos diante da necessidade de reconhecer que sistemas diferentes desempenharão diferentemente suas funções - e, talvez, que alguns sistemas desempenharão suas funções de maneira mais eficaz ou mais eficiente que outros. Se essa empreitada é bem-sucedida, isso possibilitará à Ciência Política, em princípio, estabelecer uma conceituação universalmente válida de "desenvolvimento político" (ou, se se quiser, de um indicador operacional mais modesto, o "desempenho institucional"), que possa funcionar como referência normativa, sem estar atada à presunção de que esse desenvolvimento necessariamente se dê. Persistiria o risco de fracasso do sistema, de incapacidade de desempenhar suas funções, de decadência política - enfim, da sucessão relativamente imprevisível de eventos históricos. Mas a Ciência Política poderia dispor de um critério teoricamente informado para a análise (e, inevitavelmente, para a avaliação) comparativa de diferentes casos empíricos.

Se voltarmos agora a Putnam, poderemos constatar que, em termos analíticos, o que ele faz é identificar na existência de uma "comunidade cívica" e na disseminação da cooperação e da confiança mútua no interior da população o mais eficaz e importante componente daquilo que Almond chamou de "the support aspects of capability", que configurariam aquela espécie de "reserva" do sistema político, ao determinar o seu "potencial de apoio" ("support potential"). Putnam identificou, sob o rótulo da civic community, um conjunto de características mensuráveis, presentes na sociedade, capaz de expandir formidavelmente o potencial de apoio de um sistema político, de expandir o "retorno" esperável pelo sistema a partir de suas próprias iniciativas. Efetivamente, as preocupações de Putnam dirigem-se precisamente para a agenda de pesquisa que Almond (idem, p. 112) propôs então: "The system reserve component of capability is an aspect of political culture, the 'support propensities' which are distributed among the various strata of the population, and the various roles of the political system. We have to estimate the content of this reserve, its magnitude, and its mobility, if we are going to be able to explain and predict political performance" 18 .

Claramente Almond esperava ter proporcionado, a partir do seu esquema conceitual, uma base empírico-analítica para manejar-se o sempre escorregadio conceito de "cultura política". E Putnam é certamente um capítulo relevante da história desse conceito ${ }^{19}$. Infelizmente, se Putnam estiver correto, a magnitude dessa "reserva" será muito mais rígida no tempo do que se esperaria nos anos 1960. De qualquer modo, tendo em vista o marcante conteúdo simultaneamente empírico e normativo do trabalho de Putnam (e independentemente da avaliação que se faça quanto às perspectivas da pesquisa futura em torno do tema da cultura política), as afinidades aqui esboçadas entre Putnam e Almond tornam particularmente persuasiva a rápida menção feita por Almond às possibilidades de preenchimento do hiato entre estudos normativos e "científicos" da política a partir do estudo das capabilities.

\section{AS HESITAÇÕES DO CAPITAL SOCIAL}

A face mais flagrantemente normativa da "fortuna crítica" do argumento de Putnam materializase na abundante literatura recente sobre "capital social" e - principalmente - na sua elevação a variável-chave para identificar as potencialidades de implementação bem-sucedida de políticas e programas públicos em contextos variados. Contudo, o conceito permanece insatisfatoriamente vago, portador de ambigüidades importantes que problematizam sua operacionalização teórica.

18 "O componente de reserva sistêmica da capacidade é um aspecto da cultura política, as 'propensões de apoio' que são distribuídas entre os vários estratos da população e os vários papéis do sistema político. Temos que estimar o conteúdo dessa reserva, sua magnitude e sua mobilidade, se desejamos estar aptos a explicar e predizer o desempenho político" [N. R.].

19 Cabe mencionar, contudo, a forte crítica de James Johnson (2003) à maneira, digamos, "subconceitualizada" como toda a tradição da ciência política americana nas últimas décadas aborda o tema da cultura política. 
Preliminarmente, é necessário sublinhar que a despeito da enorme popularização do conceito que produziu - o estudo de Putnam não é sobre capital social, que desempenha ali o papel de uma espécie de coadjuvante que rouba a cena nos momentos finais do filme. Pois - a julgar pelo índice remissivo da edição brasileira (PUTNAM, 1997) - o capital social só faz sua entrada no livro na página 177 , quando Putnam aponta-o como elemento facilitador da cooperação voluntária, decisiva para a instauração dos círculos virtuosos favorecedores do bom desempenho institucional - esta sim a variável dependente fundamental de todo o estudo. A partir desse ponto (ou seja, pelas últimas 18 páginas do livro), a alusão ao capital social - com sua evocação econômica - substitui com aparente vantagem as ressonâncias potencialmente chauvinistas e autoritárias da alusão a "comunidades cívicas" que permeara todo o livro até ali. Contudo, o conceito de capital social permanece surpreendentemente impreciso durante toda a exposição do capítulo final - pois Putnam jamais o define. Feita a alusão inicial ao capital social, tudo o que se segue é, inicialmente, uma remissão à exposição do conceito feita por James Coleman (apud PUTNAM, 1997, p. 241, n. 20) e outros autores, seguida por uma enumeração um tanto vaga de atributos do capital social, que jamais chega perto de uma definição.

Vejamos como Putnam (1997, p. 177) dirigese ao conceito: "Aqui o capital social diz respeito a características da organização social, como confiança, normas e sistemas, que contribuam para aumentar a eficiência da sociedade, facilitando as ações coordenadas [e passa a citar Coleman (1990, p. 302)]: 'Assim como outras formas de capital, o capital social é produtivo, possibilitando a realização de certos objetivos que seriam inalcançáveis se ele não existisse [...]"”.

Seguem-se exemplos e mais exemplos, tanto citados de Coleman quanto concebidos pelo próprio Putnam. Mas, para além do fato de não chegarmos a ter uma definição propriamente dita, a vaga enumeração de atributos do capital social peca por admitir dentro dela fenômenos de natureza fundamentalmente distinta: "confiança, normas e sistemas" admitem qualquer coisa sob o seu guardachuva. Mais precisamente, englobam simultaneamente tanto variáveis "estruturais" quanto "atitudinais", formando uma caixa-preta conceitual cujo significado teórico preciso dentro da explicação dada por Putnam para o desempenho institucional torna-se difícil de especificar.

Essa distinção não é uma questiúncula irrelevante, típica de escolasticismo acadêmico. Edwards e Foley (2001) e Foley, Edwards e Diani (2001) fazem-nos ver que, conforme caracterizamos o capital social como uma disposição atitudinal individualmente identificável ou como um atributo sócio-estrutural dependente do contexto (como a existência efetiva de redes de interação que venham a facilitar ações coletivas no interior do grupo), a natureza do argumento varia bastante - e muito especialmente o lugar nele ocupado por sua variável-chave, a confiança. No primeiro caso (fortemente sugerido pela maneira como Putnam (1997) inicialmente expôs seu argumento), a confiança interpessoal vê-se promovida a um parâmetro exógeno do sistema, constituindo-se em variável independente, principal explicação do "montante" de capital social disponível. Essa seria a versão propriamente "culturalista" do argumento. No segundo caso, se concebemos o capital social como variável "sócio-estrutural", atinente ao contexto, então se torna endógena a confiança interpessoal, que passa a ser variável dependente no modelo. Ainda capaz de produzir um efeito de feedback sobre o capital social, certamente, e de ajudar a constituir círculos virtuosos ou viciosos de cooperação ou conflito, mas agora atuando no argumento como resposta relativamente indireta a um input organizacional do contexto social em que operam as pessoas.

De fato, estudo de natureza empírica conduzido por Lúcio Rennó (2001) encontrou pouca corroboração para a hipótese da confiança como variável independente. Ao contrário, encontram-se indícios de que ela seja resultado de variáveis sócio-estruturais - particularmente a previsibilidade do comportamento alheio, tipicamente embutida na aplicação consistente de sanções e recompensas diversas. Esse resultado, a confirmar-se, endossa a concepção inicial do próprio James Coleman, que, segundo observa Andrew Greeley (2001, p. 236-239), favorecia explicitamente uma concepção "estrutural" (ou "relacional") do capital social, o que de resto é a única opção que permite plena exploração da analogia econômica que o conceito incorpora (LIN, 2001, p. 3-18).

Mas se concebemos o capital social não como atitude individual, mas como um atributo da sociedade, dependente do contexto em que operam os indivíduos, então se impõe reconhecer a 
"neutralidade" moral do capital social, no sentido de que sua presença facilita a realização de objetivos pelos atores, sejam esses objetivos moralmente ou socialmente desejáveis ou não: assim, a presença da máfia ou a constituição de uma organização criminosa controlada por traficantes de drogas significam uma expansão do estoque de capital social. Mais genericamente, a presença de assimetrias sociais pode significar que a constituição de determinadas formas de capital social potencialize seus efeitos ao propiciar oportunidades de ação que sejam assimetricamente aproveitadas. Michael Schulman e Cynthia Anderson (2001) apontam para essa possibilidade, ilustrada a partir do estudo do caso de uma comunidade têxtil do sul dos Estados Unidos, onde se constitui o que eles denominam como "capital social paternalista". O ponto relevante aqui deriva da possibilidade de que as identidades e solidariedades parciais, e os esforços correspondentes de organização, devem inevitavelmente ser vistas como fontes de capital social, independentemente do fato de que podem comprometer o potencial de apoio geral para o sistema político, o governo etc. Essa é uma implicação de adotar-se de uma concepção estrutural do capital social que é expressamente endossada por vários colaboradores do volume organizado por Edwards, Foley e Diani (2001) - e que recupera o sentido original que foi atribuído ao conceito por seus formuladores iniciais, Pierre Bourdieu (1986) e James Coleman (1988).

Se isso é assim, então ganha relevância crucial não apenas a identificação da presença ou ausência de redes interativas propiciadoras de capital social no interior de uma dada sociedade, mas sobretudo sua tipificação e contextualização - tarefa relativamente negligenciada desde que Tocqueville identificou na "arte da associação", enunciada de maneira genérica, o germe fundamental da América democrática. E, de fato, a literatura recente começa a experimentar alguns passos nessa direção. Dietlind Stolle e Thomas Rochon (2001) procuram especificar mais precisamente a teoria do capital social ao explorar os impactos que diferentes tipos de associação produzirão sobre o desenvolvimento de capital social público ${ }^{20}$. Sua presunção é que, por exemplo, associações orienta-

20 “Capital social público" é atributo genérico de uma sociedade, para além de qualquer grupo específico dentro dela (STOLLE \& ROCHON, 2001, p. 143-144). das para atividades de "rent-seeking" serão menos propensas a alimentar laços comunitários de reciprocidade que associações de proteção das escolas ou dos parques públicos de uma dada localidade. A hipótese básica subjacente ao raciocínio - preliminarmente corroborada pelos dados apresentados - é que a variável crucial para determinar-se o impacto potencial de uma dada associação sobre o capital social público será a inclusividade da associação: operacionalmente, o grau de diversidade de seus membros (idem, 2001, p. 144).

Aparentemente, haverá várias maneiras de procurar-se incorporar os matizes envolvidos na investigação do papel das associações na operação da democracia (WARREN, 2001). Para além dos tipos de associação identificados segundo a natureza do issue tratado e a heterogeneidade social de seus membros, como em Stolle e Rochon (2001), diversas variáveis podem em princípio ser consideradas: permitindo-me simplesmente mencionar o que me vem à mente de maneira bastante imediata, pode-se distinguir entre associações de filiação voluntária e compulsória, assim como por seu processo de constituição - se "espontâneo" ou induzido a partir de elites externas ao grupo. Seja como for, a consideração de todos esses matizes na análise da relação entre capital social e democracia recomenda-nos cautela ao tomarem-se indicadores nacionais (ou regionais) de capital social apoiados na agregação de dados de surveys em grandes "médias" - pois, como lembram-nos Foley, Edwards e Diani (2001, p. 267-270), a adoção de tal procedimento pode-nos levar a perder de vista as complexidades envolvidas no problema.

\section{DESCONFIANDO DA CONFIANÇA}

Isso nos traz de volta à consideração do papel da confiança no argumento sobre os impactos políticos do capital social. A categoria-chave do raciocínio sugerido por Putnam para conferir plausibilidade analítica à sua explicação do desempenho institucional tem recebido atenção crescente na literatura - um processo amplificado após o sucesso do trabalho de Putnam (1997), certamente, mas que o antecedeu pelo menos no trabalho seminal de Diego Gambetta (1988), referência importante para o próprio Putnam.

No contexto do Brasil, todavia, ganha irrecusável saliência o tratamento que é dado à confiança pela Pesquisa Mundial sobre Valores (World Values Survey), coordenado por Ronald Inglehart a partir da Universidade de Michigan. 
Em parte por limitações próprias a um questionário de survey restrito a questões atitudinais, ali a confiança é tratada de maneira muito simples, pelas respostas a uma questão dicotômica em que o entrevistado opta entre declarar de um modo geral se se pode ou não confiar na maioria das pessoas. Sua simplicidade suscita uma variedade problemática de interpretações possíveis, mas seu interesse entre nós decorre do fato de que o Brasil tem resultado ser uma espécie de campeão mundial da desconfiança, com um consistente padrão de respostas em que mais de $90 \%$ da população opta por responder que não se pode confiar na maioria das pessoas (INGLEHART, 1997, p. 174, 359).

É verdade que em um dado como esse a confiança apresenta-se como uma caixa-preta conceitual, passível de variadas interpretações. Está implícita na rationale da pergunta a concepção da confiança como um atributo individual que responde de maneira relativamente previsível (e, em princípio, relativamente homogênea) a certos estímulos do contexto social em que operam esses indivíduos, acabando por configurar uma "síndrome" coletiva a partir da qual se identificaria um indicador de certa "cultura política" específica, favorável ou não à boa operação das instituições políticas naquela dada sociedade. É claro que isso passa ao largo dos variados sentidos que a alusão à confiança no contexto do survey podem evocar no entrevistado: para além do problema - em si mesmo exasperantemente complexo - de produzirem-se traduções "confiáveis" de um questionário de survey em pesquisas comparativas internacionais (BEHLING \& LAW, 2000), João Feres Jr. e José Eisenberg (no prelo) propiciamnos alentada discussão dos labirintos semânticos em que nos enredamos ao passarmos da palavra inglesa trust, de raiz germânica, para a portuguesa "confiança", com origem na latina fides. Seria possível acrescentar ainda ressonâncias da palavra inglesa people, presente na formulação original da questão, que também significa "povo" - com conotações drasticamente distintas da alusão em português às "pessoas". Seja como for, no entanto, um resultado empírico consistentemente replicado deve poder ser explicado. E o padrão de respostas observado no Brasil para questões de confiança é fortemente atípico também quando comparado a outros países latinos - e tem resistido às tentativas de replicação realizadas até aqui.

Em todo caso, é fato que o conceito de confiança comporta matizes pelo menos tão relevantes quanto aqueles que dizem respeito ao capital social. Recentemente, Susanne Lundåsen (2002) levou a cabo um levantamento detalhado dos múltiplos significados que o termo compor$\mathrm{ta}^{21}$. Ali se identificam pelo menos 15 significados distintos para confiança interpessoal, que Couch e Jones (apud Lundåsen, 2002, p. 310) sintetizaram em três níveis fundamentais: "confiança generalizada" (voltada para a "natureza humana", a humanidade como um todo), "confiança relacional" (voltada para pessoas específicas, "conhecidos") e "confiança na rede" (nível intermediário, voltado para redes sociais ou familiares). Parece bastante evidente que Putnam (1997) pensa na confiança generalizada em sua teoria: ela seria gerada e realimentada pelas redes horizontais de cooperação recíproca disseminadas no interior de uma população. Sua carência entravaria processos cooperativos espontâneos que de outra maneira poderiam vir a desonerar as instituições políticas, favorecendo seu desempenho.

Desse ponto de vista, talvez fosse de esperarse uma forte correlação entre confiança interpessoal ("generalizada" ou "na rede") e confiança nas instituições. Contudo, não é o que se observa. Kenneth Newton (1999), ao contrário, constata que elas relacionam-se fracamente, e Foley, Edwards e Diani (2001, p. 269) acrescentam que isso sequer chega a ser surpreendente, tendo em vista os problemas de natureza estatística provocados pela utilização de médias nacionais. Contudo, não obstante a pertinência das ponderações levantadas, que efetivamente recomendam pesquisa empírica mais detalhada, é justo admitir que o mecanismo pelo qual Putnam vincula a confiança interpessoal ao desempenho institucional não necessariamente passa pela mistura de ambos comportada na confiança nas instituições. Conforme já foi apontado aqui em variadas passagens, o mecanismo apóia-se em uma dinâmica social virtuosa que facilitaria a operação das instituições políticas, em princípio de maneira largamente independente da opinião que os cidadãos mantivessem acerca de seu governo ou de suas instituições. Deve-se admitir, a propósito, que cidadãos "cívicos", confiantes uns nos outros, poderão tender a cultivar em relação às suas instituições uma atitude vigilante e crítica, de

21 Sou grato a Maria Aparecida Machado Pereira por chamar minha atenção para o trabalho de Lundåsen. 
efeitos potencialmente corrosivos quanto a indicadores de "confiança institucional". Ronald Inglehart (1997, p. 293-323) concilia em termos análogos a decadência da confiança nos governos e nas instituições políticas registrada no Ocidente durante as últimas décadas com sua postulação de uma "mobilização cognitiva" que resultaria em um paralelo aumento da intervenção direta dos cidadãos em assuntos públicos ${ }^{22}$. E Russell Hardin (1999) traça distinção cuidadosa entre confiança no governo e confiança individual induzida por bom governo, antes de problematizar ricamente os significados possíveis do ato de confiar-se em instituições ou organizações, e de se perguntar seriamente até que ponto a confiança em governos é sequer desejável. Sob essa perspectiva, é impossível recusar liminarmente a pergunta sobre até que ponto a presença de "capital social" e "confiança" (interpessoal ou nas instituições) não poderia eventualmente ser vista como manipulação ideológica bem-sucedida.

\footnotetext{
22 Reis e Castro (2001) depararam-se com resultado que pode ser interpretado de modo análogo: se a propensão a endossar normas éticas socialmente estabelecidas - como solidariedade e altruísmo - aumenta com a sofisticação política, por outro lado aumenta igualmente a propensão a um comportamento oportunista diante de circunstâncias desfavoráveis. Ou seja, o "cívico" e o "cínico" não são necessariamente duas pessoas, mas a mesma: o indivíduo mais sofisticado tende tanto a vocalizar mais prontamente a norma coletivamente aceita quanto a fexibilizar a sua aplicação a partir de uma avaliação lúcida do seu contexto.
}

\section{NOTAS FINAIS: RUMO A UMA TEORIA OPERACIONALIZÁVEL?}

Ao cabo, resta a percepção de uma agenda de pesquisa certamente promissora, mas patentemente "imatura", do ponto de vista tanto da operacionalização empírica da teoria quanto mesmo da especificação analítica precisa do significado de suas categorias centrais. E aqui parece operar um curioso paradoxo. Se o "capital social" aparece inicialmente como um conceito "guarda-chuva" um tanto vago e aparentemente intratável, sua origem em categoria analítica de significado razoavelmente preciso e - sobretudo - larga tradição em economia ("capital") parece propiciarlhe uma pista por onde uma teorização minimamente sistemática pode avançar. O recente trabalho de Nan Lin (2001) constitui certamente um passo encorajador nessa direção. Infelizmente, temo que talvez o oposto dê-se com o papel reservado à confiança nessa problemática. De uso corrente na vida cotidiana de povos do mundo todo, e (por isso mesmo) de enorme poder sugestivo na exposição original do argumento de Putnam, receio que a precisão analítica do lugar da confiança no argumento venha a ser irremediavelmente comprometida pela polissemia em que se enreda - particularmente quando, diferentemente do que se passa com o capital social, não resistimos à tentação de alcançá-la por meio de perguntas diretas, talvez excessivamente simples, em nossos surveys atitudinais. Será crucial, talvez, para a preservação de seu papel em uma teoria empírica da democracia, mostrarmo-nos capazes de traduzir o que esperamos da confiança em padrões comportamentais observáveis.

Bruno Pinheiro W. Reis (brunopwr@fafich.ufmg.br) é Doutor em Ciência Política pelo Instituto Universitário de Pesquisas do Rio de Janeiro (IUPERJ) e Professor do Departamento de Ciência Política da Universidade Federal de Minas Gerais (UFMG).

\section{REFERÊNCIAS BIBLIOGRÁFICAS}

ALMOND, G. A. 1966. A Developmental Approach to Political Systems. In: FINKLE, J. L. \& GABLE, R. W. (eds.). Political Development and Social Change. Nova York : John Wiley \& Sons.

ALMOND, G. A. \& POWELL JR., G. B. 1966. Comparative Politics : A Developmental Approach. Boston : Little Brown.
AXELROD, R. 1984. The Evolution of Cooperation. Nova York: Basic Books.

BEHLING, O. \& LAW, K. S. 2000. Translating Questionnaires and Other Research Instruments : Problems and Solutions. Thousand Oaks : Sage.

BINDER, L. et alii. 1971. Crises and Sequences in Political Development. Princeton : Prin- 
ceton University Press.

BOURDIEU, P. 1986. The Forms of Capital. In : RICHARDSON, J. (ed.). Handbook of Theory and Research for the Sociology of Education. Nova York: Greenwood Press.

BURKHART, R. E. \& LEWIS-BECK, M. S. 1994. Comparative Democracy : The Economic Development Thesis. American Political Science Review, Washington, D.C., v. 88, n. 4, p. 903-910, Dec.

COLEMAN, J. S. 1988. Social Capital in the Creation of Human Capital. American Journal of Sociology, Chicago, v. 94, Supplement, p. S95S120.

1990. Foundations of Social Theory. Cambridge, Mass. : Harvard University Press.

COUCH, L. L. \& JONES, W. H. 1997. Measuring Levels of Trust. Journal of Research in Personality, New York, v. 31, n. 3, p. 317-336, Sept.

DAHL, R. A. 1997. Poliarquia : participação e oposição. São Paulo : USP.

EDWARDS, B. \& FOLEY, M. W. 2001. Civil Society and Social Capital : A Primer. In : EDWARDS, B., FOLEY, M. W. \& DIANI, M. (eds.). Beyond Tocqueville : Civil Society and the Social Capital Debate in Comparative Perspective. Hanover, NH : University Press of New England.

EDWARDS, B., FOLEY, M. W. \& DIANI, M. (eds.). 2001. Beyond Tocqueville: Civil Society and the Social Capital Debate in Comparative Perspective. Hanover, NH : University Press of New England.

FERES JR., J. \& EISENBERG, J. no prelo. Dormindo com o inimigo : uma crítica analítica ao conceito de confiança. In : SOUZA, J. (org.). Reconhecimento, direitos e democracia em perspectiva global: um diálogo Norte-Sul. Belo Horizonte : UFMG.

FOLEY, M. W., EDWARDS, B. \& DIANI, M. 2001. Social Capital Reconsidered. In : EDWARDS, B., FOLEY, M. W. \& DIANI, M. (eds.). Beyond Tocqueville: Civil Society and the Social Capital Debate in Comparative Perspective. Hanover, NH : University Press of New England.
GAMBETTA, D. 1988. Can We Trust Trust? In : GAMBETTA, D. (org.). Trust : Making and Breaking Cooperative Relations. Oxford : Basil Blackwell.

GEDDES, B. 1994. Politician's Dilemma : Building State Capacity in Latin America. Berkeley : University of California Press.

GOLDBERG, E. 1996. Thinking About How Democracy Works. Politics and Society, London, v. 24, n. 1, p. 7-18, Mar.

GREELEY, A. 2001. Coleman Revisited: Religious Structures as a Source of Social Capital. In : EDWARDS, B., FOLEY, M. W. \& DIANI, M. (eds.). Beyond Tocqueville : Civil Society and the Social Capital Debate in Comparative Perspective. Hanover, NH : University Press of New England.

HARDIN, R. 1999. Do We Want Trust in Government? In: WARREN, M. E. (ed.). Democracy and Trust. Cambridge : Cambridge University Press.

HUNTINGTON, S. P. 1975. A ordem política nas sociedades em mudança. Rio de Janeiro : Forense-Universitária.

INGLEHART, R. 1997. Modernization and Postmodernization : Cultural, Economic, and Political Change in 43 Societies. Princeton : Princeton University Press.

JACKMAN, R. W. \& MILLER, R. A. 1998. Social Capital and Politics. Annual Review of Political Science, Palo Alto, CA, v. 1, p. 4773, June.

JOHNSON, J. 2003. Conceptual Problems as Obstacles to Progress in Political Science : Four Decades of Political Culture Research. Journal of Theoretical Politics, London, v. 15, n. 1, p. 87-115, Jan.

KORNHAUSER, W. 1959. The Politics of Mass Society. Glencoe : The Free Press.

LEVI, M. 1990. A Logic of Institutional Change. In : COOK, K. S. \& LEVI, M. (eds.). The Limits of Rationality. Chicago : The University of Chicago Press.

1996. Social and Unsocial Capital : A Review Essay of Robert Putnam's Making Democracy Work. Politics and Society, London, v. 24, n. 1, p. 45-55, Mar. 
LIMONGI, F. P. 1989. O Federalista : remédios republicanos para males republicanos. In : WEFFORT, F. C. (org.). Os clássicos da política. V. I. São Paulo : Ática.

LIN, N. 2001. Social Capital : A Theory of Social Structure and Action. Cambridge : Cambridge University Press.

LUNDÅSEN, S. 2002. Podemos confiar nas medidas de confiança? Opinião Pública, Campinas, v. VIII, n. 2, p. 304-27, out.

NEWTON, K. 1999. Social and Political Trust in Established Societies. In : NORRIS, P. (ed.). Critical Citizens : Global Support for Democratic Governance. Oxford : Oxford University Press.

OLSON JR., M. 1965. The Logic of Collective Action : Public Goods and the Theory of Groups. Cambridge, Mass. : Harvard University Press.

PRATES, A. A. 1997. Resenha de Making Democracy Work, de Robert Putnam. Teoria \& Sociedade, Belo Horizonte, n. 1, p. 193-201.

PUTNAM, R. D. 1997. Comunidade e democracia : a experiência da Itália moderna. Rio de Janeiro : Fundação Getúlio Vargas.

REIS, F. W. \& CASTRO, M. M. M. 2001. Democracia, civismo e cinismo : um estudo empírico sobre normas e racionalidade. Revista Brasileira de Ciências Sociais, São Paulo, v. 16, n. 45, p. $25-46,1^{\circ}$ semestre.

RENNÓ, L. R. 2001. Confiança interpessoal e comportamento político : microfundamentos da teoria do capital social na América Latina. Opinião Pública, Campinas, v. VII, n. 1, p. 33-59, maio.

SANTOS, W. G. 1993. Razões da desordem. Rio de Janeiro : Rocco.

SCHULMAN, M. D. \& ANDERSON, C. 2001. The Dark Side of the Force : Economic Restructuring and Social Capital in a Company Town. In : EDWARDS, B., FOLEY, M. W. \& DIANI, M. (eds.). Beyond Tocqueville : Civil Society and the Social Capital Debate in Comparative Perspective. Hanover, NH : University Press of New England.

STOLLE, D. \& ROCHON, T. R. 2001. Are All Associations Alike? Member Diversity, Associational Type, and the Creation of Social Capital. In : EDWARDS, B., FOLEY, M. W. \& DIANI, M. (eds.). Beyond Tocqueville : Civil Society and the Social Capital Debate in Comparative Perspective. Hanover, NH : University Press of New England.

TARROW, Sidney. 1996. Making Social Science Work Across Space and Time : A Critical Reflection on Robert Putnam's Making Democracy Work. American Political Science Review, Washington, D.C., v. 90, n. 2, p. 389397, July.

TAYLOR, M. 1976. Anarchy and Cooperation. Londres : John Wiley \& Sons.

1987. The Possibility of Cooperation. Cambridge : Cambridge University Press.

WARREN, M. E. 2001. Democracy and Association. Princeton : Princeton University Press.

WORLD BANK. 2003. Social Capital for Development. Washington, D.C. : The World Bank Group. http://www.worldbank.org/poverty/scapital. Acesso em : ago.2003.

ZAGARE, F. C. 1984. Game Theory : Concepts and Applications. Beverly Hills : Sage. 